\title{
In Memoriam: Gerhard Jagschitz (1940-2018). Ein persönlicher Nachruf
}

\section{Oliver Rathkolb}

\section{(2) OpenEdition}

1 Journals

\section{Édition électronique}

URL : http://journals.openedition.org/austriaca/656

DOI : 10.4000/austriaca.656

ISSN : 2729-0603

\section{Éditeur}

Presses universitaires de Rouen et du Havre

\section{Édition imprimée}

Date de publication : 1 juin 2018

Pagination : 245-247

ISBN : 979-10-240-1233-9

ISSN : 0396-4590

\section{Référence électronique}

Oliver Rathkolb, „In Memoriam: Gerhard Jagschitz (1940-2018). Ein persönlicher Nachruf“, Austriaca [Online], 86 | 2018, Online erschienen am: 01 Juli 2020, abgerufen am 30 Januar 2021. URL: http:// journals.openedition.org/austriaca/656 ; DOI: https://doi.org/10.4000/austriaca.656 


\title{
Des idées et des faits
}

\author{
In Memoriam: Gerhard Jagschitz (1940-2018) \\ Ein persönlicher Nachruf
}

Mit großer Trauer schreibe ich diesen Nachruf auf einen bedeutenden Zeithistoriker, der nicht nur Wissenschaftler, sondern auch ein engagierter Demokrat und Akteur der Zivilgesellschaft gewesen ist. Jagschitz gehörte der zweiten Generation der Zeithistoriker in Österreich an und begann seine Karriere als Assistent bei Ludwig Jedlicka 1968 mit einer leider nie publizierten, spannenden Dissertation über „Die Jugend des Bundeskanzlers Engelbert Dollfuß“. Sein erstes Buch, mit dem er sich 1978 habilitierte, war dem gescheiterten Putschversuch der Nationalsozialisten 1934 gewidmet.

1985 wurde er Universitätsprofessor für Neuere Geschichte mit besonderer Berücksichtigung der Zeitgeschichte. Zwischen 1994 und 2001 war er überdies ein sehr aktiver Vorstand des Instituts für Zeitgeschichte.

Vom frühesten Beginn seiner Tätigkeit am Institut für Zeitgeschichte an begann er, neben seiner umfangreichen und sehr erfolgreichen Lehr- und Forschungstätigkeit eines der bedeutendsten zeitgeschichtlichen Bildarchive in Österreich aufzubauen und engagierte sich intensiv mit Gleichgesinnten an der Institutionalisierung audiovisueller Quellensammlungen. Wichtige Bildbände beispielsweise aus der Sammlung des Starphotographen Lothar Rübelt dokumentieren eindrucksvoll diese Arbeit.

Jetzt befinden sich - mit seiner Zustimmung - diese seine Sammlungen im Bildarchiv der Österreichischen Nationalbibliothek bzw. - was die Tonquellen betrifft - in der Mediathek des Technischen Museums, mit der er ein umfangreichreiches Oral History Projekt in mehrstündigen lebensgeschichtlichen Gesprächen mit über 1.500 Männern und Frauen, Jugendlichen Erwachsenen und Senioren durchgeführt hat.

Gerhard Jagschitz war ein wesentlicher Pionier im Bereich der Dokumentation und Verwendung audiovisueller Quellen und hat überdies in seinen theoretischen Arbeiten international Anerkennung gefunden. Gerhard Paul, eine der bedeutendsten Bildtheoretiker der Gegenwart, 
wies darauf hin, dass Jagschitz als erster im deutschsprachigen Bereich den Begriff „Visual History“ verwendet hat.

Jagschitz war ebenso als Ausstellungsgestalter in Niederösterreich erfolgreich - u.a. mit Themen wie 1985 auf der Schallaburg „Die wilden 5 oiger Jahre“ oder mit Stefan Karner gemeinsam 1995 mit „Menschen nach dem Krieg. Schicksale 1945-1955“. Es war Jagschitz ein großes Anliegen, zeitgeschichtliche Themen in gediegener wissenschaftlicher Form einer breiten Öffentlichkeit näher zu bringen.

Ich selbst habe bei Jagschitz mein erstes Seminar absolviert, und er hat mich von der mittelalterlichen Geschichte zur Zeitgeschichte weggelockt. Mit Dankbarkeit erinnere ich mich an seine perfekte umfassende Betreuung meiner Dissertation in der Zeit des Interregnums zwischen Jedlicka und Erika Weinzierl. Er war ein engagierter und kompetenter akademischer Lehrer wie zahlreiche andere ehemalige Studenten bestätigen können.

Durch seine Gutachten in Neonaziprozessen, die auf umfassenden Quellenforschungen zur Geschichte des Holocaust beruhten, ermöglichte er eine klare Rechtsprechung gegen Neonazis und deren permanente Verleugnung des Holocaust.

Jagschitz scheute sich nicht, kritisch in die eigene Familiengeschichte zu blicken und in einem Buch über seinen Großvater Max Ronge, der bis zum Ende der Monarchie Chef des Geheimdienstes der k. u. k. Armee war, gemeinsam mit Verena Moritz und Hannes Leidinger unter dem Titel „Im Zentrum der Macht“ (2007), dessen Tätigkeit zu rekonstruieren: „Mein Großvater“, meinte Gerhard Jagschitz in einem Interview für Die Zeit 2007, „war nach den heute gültigen Regeln ein Massenmörder.“ Ein vergleichbares Statement findet sich selten, aber dokumentiert die strenge wissenschaftliche Prägung des Zeithistorikers Jagschitz.

Ebenso streng ging Jagschitz immer wieder mit dem Zustand der politischen Kultur in Österreich und Europa ins Gericht. Er sah die EU primär als Gefahr für die Souveränität Österreichs an, aber kritisierte ebenso den Zustand der Politik in Österreich, wenn er einen „bananenrepublikanischen Hauch "im Zusammenhang mit dem EurofighterAusschuss konstatierte. Schon als Mittelbauvertreter an der Universität Wien hat er sich erfolgreich für die Basisdemokratie engagiert und blieb in vielen Bereichen zivilgesellschaftlichen Gruppen eng verbunden.

Gerhard Jagschitz und seine durchaus scharfen und pointierten Stellungnahmen werden fehlen, seine zeitgeschichtlichen Studien und seine 
umfangreichen Sammlungen hingegen werden die Erinnerung an ihn und eine kritische österreichische Zeitgeschichte wach halten.

Oliver RATHKOLB

\section{Historias cruzadas X Gekreuzte Geschichten.}

Ein interdisziplinäres Gedenkprojekt über den

März 1938, Diktatur, Exil und Migration im globalhistorischen Licht österreichisch-mexikanischer Beziehungen

In das multiple österreichische Gedenkjahr 2018 fand auch die Globalgeschichte Eingang. Der Historiker Berthold Molden konzipierte gemeinsam mit KünstlerInnen und KulturwissenschaftlerInnen eine interdisziplinäre und transnationale Veranstaltungsreihe. Zentrum ist ein globaler Erinnerungsort: der Mexikopatz in Wien.

Der Mexikoplatz verdankt seinen Namen der Erinnerung an den Protest gegen die Annexion Österreichs durch das Deutsche Reich, den Mexiko im März 1938 als einziges Land vor dem Völkerbund erhob. Dieser Moment war nicht nur für die österreichische Geschichte bedeutsam, sondern auch für die Globalgeschichte des 20. Jahrhunderts. Das kleine Österreich verschwand von der Landkarte. Und das ferne, eben aus einer langen Revolution hervorgegangene Mexiko legte dagegen einsamen Protest ein, während es sich selbst gegenüber dem mächtigen Nachbarn USA zu behaupten versuchte - ein historischer Berührungspunkt, der in vielerlei Hinsicht auf die globalen Entwicklungslinien dieses „Zeitalters der Extreme" verweist.

Doch neben diesem Schlüsseldatum, in das Diktatur und Exil eingeschrieben sind, haben auch andere Dimensionen des 20. Jahrhunderts auf dem Mexikoplatz Spuren hinterlassen: das Rote Wien der $20 e r$ und 3oer Jahre, die Remigration nach 1945, die Ankunft von GastarbeiterInnen in den 6oer und 7oer Jahren, die Immigration sowjetischer Jüdinnen und Juden in den 8oer Jahren und zuletzt Geflüchtete aus Afrika und dem Nahen Osten. Da all diese Gedächtnis-Schnittstellen transnationale Bezüge haben, machen sie den Mexikoplatz zu einem globalen Ort. Das Projekt „Gekreuzte Geschichten“ schafft durch die Aktualisierung von Geschichte mit künstlerischen Mitteln neue Identitätsangebote und 